\title{
Deciding geochemical factor for incorporation of metal ions in vacant sites of non-stoichiometric hydroxyapatite
}

\author{
NitiN KUMAR KHANDELWAL ${ }^{1}$ GOPALA KRISHNA
} DARBHA $^{2}$

${ }^{1}$ nkk17ip016@iiserkol.ac.in ${ }^{2}$ gkdarbha@gmail.com Environmental Nanoscience Laboratory, Indian Institute of Science Education and Research Kolkata, Kolkata, Mohanpur, West Bengal, India- 741246

Sustainability in terms of water demands improved water quality and clean water resources which face anthropogenic inputs with persistent heavy metals as a major hurdle. Incorporation of a metal ion in vacant sites of a mineral can be a good option for its permanent removal and is affected by many factors including ionic radius and charge. Ions with higher Ionic potential, easily partition to solids while vacant sites can handle ions with similar size and charge.

To compare and evaluate the deciding factor between these two, in this work, mineral hydroxyapatite (HAP), $\mathrm{Ca}_{10}\left(\mathrm{PO}_{4}\right)_{6}(\mathrm{OH})_{2}$ was synthesized in laboratory by varying the $\mathrm{Ca} / \mathrm{P}$ ratio to generate non-stoichiometry and therefore vacant $\mathrm{Ca}$ sites [1]. We have synthesized two HAPs with $\mathrm{Ca} / \mathrm{P}=1.67$ (St-HAP) and $\mathrm{Ca} / \mathrm{P}=1.3$ (Non-St-HAP). As the ionic radius of $\mathrm{Ca}^{2+}$ is $0.99 \AA$ and therefore two toxic metals i.e. Zinc and Cadmium with similar charge i.e. +2 and different ionic radius i.e. $0.74 \AA$ and $0.95 \AA$ were selected as adsorbate. Comparatively evaluation of adsorption efficiency was done by supplying the adsorbate separately while mixture of $\mathrm{Cd}^{2+}$ and $\mathrm{Zn}^{2+}$ was supplied to compare the selective crystal incorporation of ions.

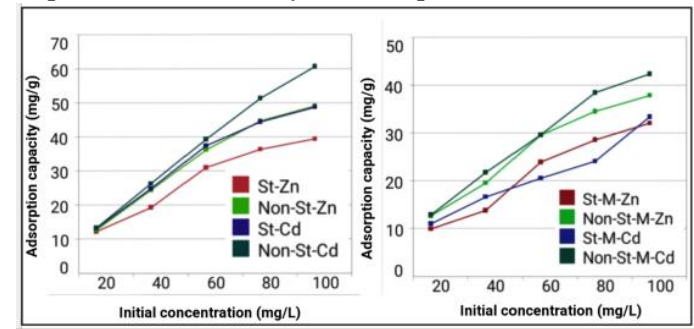

Fig.1 Adsorption of Zinc and Cadmium separately (left) and in mixture (right) on St-HAP and Non-St-HAP

Results in figure-1 clearly shows that nonstoichiometry results in increased sorption capacity for both $\mathrm{Cd}^{2+}$ and $\mathrm{Zn}^{2+}$ due to increased surface area, while similar size of $\mathrm{Cd}^{2+}$ as of $\mathrm{Ca}^{2+}$ results in higher cadmium removal in the mixture of metal ions even if $\mathrm{Zn}^{2+}$ has higher ionic potential and therefore higher affinity towards solid compared to $\mathrm{Cd}^{2+}$.

[1] Y. Sekine, R. Motokawa, N. Kozai, T. Ohnuki, D. Matsumura, T. Tsuji, R. Kawasaki, K. Akiyoshi, Calcium-deficient Hydroxyapatite as a Potential Sorbent for Strontium, Sci Rep-Uk, 7 (2017) 2064. 